\title{
Macroeconomic impacts of cigarette consumption in Pakistan
}

\author{
Wasim Saleem (10 , Mohammad Asif Iqbal
}

Social policy and development centre, Karachi, Pakistan

\section{Correspondence to}

Wasim Saleem, Social policy and development centre, Karachi, Pakistan; wasaleem@gmail.com

Received 28 January 2020 Revised 6 September 2020 Accepted 10 September 2020 Published Online First 6 November 2020

\section{ABSTRACT}

Background Pakistan has a large population of tobacco users, with about 24 million adults consuming tobacco products in one form or another. There is a dearth of research on the impact of a reduction in tobacco use on Pakistan's economy which can inform policy-makers on the extent that tobacco control measures would affect macroeconomic indicators such as output and employment.

Objectives The objective of this study is to quantify the changes in output, income and employment resulting from changes in cigarette consumption and to quantify the impact of such changes on the overall economy. Methodology The study uses the input-output table for the fiscal year 2010-2011 for Pakistan's economy, to estimate the output, income and employment multipliers. The Leontief input-output model is used to estimate the sectorwise multiplier effects. It estimates direct, indirect and consumption-induced effects of changes in tobacco use on the economy.

Results The cigarette industry's share in large-scale manufacturing and industrial employment is $1.1 \%$ and $0.3 \%$, respectively. The estimates of gross output, income and employment multipliers for the cigarette industry have relatively small magnitudes indicating minimal impact on the economy. A simulation analysis based on the latest estimates of price elasticity of cigarette and input-output multipliers, shows that a 10\% increase in price will lead to an $11 \%$ reduction in cigarette consumption, which translates into annual savings of Pakistani Rupees (Rs) 16 billion by households. Reduction in cigarette consumption will allow individuals to spend their savings on other commodities. For example, spending this amount on food items will lead to a net increase of Rs 40 billion annual output of the economy. Conclusion Reduction in tobacco consumption will lead to initial losses to the economy but there will be considerable gains in output, employment and income due to redistribution of tobacco expenditures.

\section{INTRODUCTION}

Pakistan is among the high-burden countries with respect to the prevalence of tobacco use and its implications for public health. According to Global Adult Tobacco Survey 2014, 19.1\% of adults in Pakistan used tobacco in any form, which translates into a population of about 24 million adults. Consequently, the prevalence of tobacco-related diseases is also high and various estimates indicate that tobacco use is associated with more than 108800 deaths every year in the country. ${ }^{1}$ Tobacco taxation is being used as a policy measure at the governmental level for tobacco control in Pakistan. However, it is also argued that the tobacco industry is not only making a significant contribution to large-scale manufacturing, but is also creating direct and indirect employment in the country. ${ }^{23}$

Several studies have shown that the demand for cigarettes and other tobacco products is significantly and negatively correlated with the price of cigarettes in Pakistan. ${ }^{3-8}$ Further, due to the passthrough effect of tobacco taxes on the price of cigarettes, a $10 \%$ increase in tobacco taxes will increase the price of cigarettes by $8 \% .^{9}$ However, no prior studies estimated the impact of a reduction in tobacco use on the tobacco industry, in general and the economy.

\section{OBJECTIVE}

The main objective of this research is to analyse the macroeconomic impacts of tobacco use in Pakistan. Focusing on the cigarette manufacturing industry in Pakistan, the study estimates the impact of changes in final demand of cigarettes on the output, income and employment in the country. The final demand for cigarettes may be influenced by several factors, including taxes and non-price factors. However, this paper focuses only on the final demand and treats the impact of price changes on the cigarette demand exogenously without looking into the relationship between prices and tax rate.

The organisation of this paper is as follows. Section 3 provides a profile of the tobacco sector in Pakistan, including the contribution of tobacco in agricultural output and employment, and its share in industrial output in the economy. The inputoutput structure of the cigarette industry, including share of wages and consumption, is presented in section 4. Section 5 deals with data and methodology. Results and conclusions are presented in sections 6 and 7 , respectively.

THE PROFILE OF TOBACCO SECTOR IN PAKISTAN Pakistan ranked ninth in the world in raw tobacco production in $2016 .^{10}$ Despite being one of the largest tobacco-growing countries, tobacco remains a relatively minor crop in the agriculture sector of Pakistan, both in terms of area under cultivation and value of production. Currently, tobacco crop accounts for only $0.42 \%$ of the total value of agricultural produce.

The area under the tobacco crop has not exceeded $0.25 \%$ of the total land under cultivation in the last two decades. As shown in table 1, an area of 56000 hectares was devoted to tobacco cultivation in 1999-2000, which declined to 47000 hectares by $2017-2018$. Although it fluctuated until 20142015, a consistent declining trend was observed in recent years. Correspondingly, the percentage share 


\begin{tabular}{lllll}
\hline Table 1 & Area under cultivation and tobacco production & \\
\hline & $\begin{array}{l}\text { Total cropped } \\
\text { area } \\
\text { (million hectares) }\end{array}$ & $\begin{array}{l}\text { Area under } \\
\text { tobacco } \\
\text { (000 hectares) }\end{array}$ & $\begin{array}{l}\text { Share of area } \\
\text { under tobacco } \\
\text { cultivation }(\%)\end{array}$ & $\begin{array}{l}\text { Production } \\
\text { of tobacco } \\
\text { (000 Tonnes) }\end{array}$ \\
\hline Years & 56 & 0.25 & 108 \\
\hline $1999-2000$ & 22.7 & 50 & 0.22 & 101 \\
\hline $2004-2005$ & 22.8 & 56 & 0.23 & 119 \\
\hline $2009-2010$ & 23.9 & 51 & 0.22 & 103 \\
\hline $2010-2011$ & 22.7 & 46 & 0.20 & 98 \\
\hline $2011-2012$ & 22.5 & 50 & 0.22 & 108 \\
\hline $2012-2013$ & 22.6 & 49 & 0.22 & 130 \\
\hline $2013-2014$ & 22.2 & 54 & 0.23 & 120 \\
\hline $2014-2015$ & 23.3 & 53 & 0.22 & 116 \\
\hline $2015-2016$ & 23.7 & 47 & 0.20 & 100 \\
\hline $2016-2017$ & 23.3 & 47 & 0.20 & 100 \\
\hline $2017-2018$ & 23.3 & 57 &
\end{tabular}

Source: Economic Survey of Pakistan, Finance Division, Government of Pakistan.

of tobacco in the total cropped area also declined from 0.25 to 0.2 during the same period.

In 2018, Pakistan produced 100000 tonnes of raw tobacco. On average, the level of raw tobacco production in the country remained slightly over 100000 tonnes during 1999-2000 and 2017-2018. It peaked in 2013-2014 (130000 tonnes) and showed a downward trend thereafter. The decrease in production somewhat corresponds to the decrease in the area under cultivation. The level of farm employment is also low in the sector. According to estimates, based on Pakistan's Labour Force Survey (LFS) 2014-2015, only 8200 people are employed in the growing of tobacco, which constitutes only $0.03 \%$ of the total agriculture employment in the country.

Similar to tobacco cropping, the contribution of the cigarette industry in the economy is also small in terms of output and employment. Estimates show that the share of the cigarette industry in total industrial output (in terms of the value of production) was only $1.11 \%$ in 2017-2018; it has decreased from $1.63 \%$ in 2010-2011 (table 2). The price increase was the main cause of this decline in the production of cigarettes as the prices of cigarettes increased by $84 \%$ during this period. Correspondingly, the share of the cigarette industry in the overall employment also declined from $0.5 \%$ in $2010-2011$ to $0.3 \%$ in 2017-2018. According to the estimates based on LFS 20142015 , only 23000 people were employed in this sector, which include both formal and informal manufacturing of cigarettes and is computed based on the weighted share of employment of the tobacco industry in total employment.

Between 2001 and 2018, the average domestic production of cigarettes was 60 billion sticks; the average per annum imports and exports during this period was 0.6 billion sticks and 0.4 billion sticks per annum, respectively. So, domestic

Table 2 Share of the cigarette industry in the production and employment

\begin{tabular}{lll}
\hline Years & Share in industrial production* & Share in industrial employment \\
\hline $2010-2011$ & 1.63 & 0.5 \\
$2014-2015$ & 1.37 & 0.3 \\
$2017-2018$ & 1.11 & - \\
\hline
\end{tabular}

Source, Economic Survey of Pakistan and Labour Force Survey of Pakistan.

*At constant factor cost of 2005-2006.
Table 3 Input-output structure of the cigarette industry (Rs million)

\begin{tabular}{lc}
\hline & Cigarette industry \\
\hline Agriculture & 27530 \\
\hline Industry & 42101 \\
Services & 213418 \\
A.Intermediate input use across sector & 283049 \\
B.Value added & 286993 \\
C.Total Value of output (A+B) & 570041 \\
\hline
\end{tabular}

Source: Input-output table of Pakistan economy 2010-2011, prepared by Federal Board of Revenue (FBR).

production is the primary source of consumption of cigarettes in Pakistan.

The above indicator shows that the magnitude of the tobacco industry is relatively small. A change in the final demand for the product will have a relatively small effect on the economy. But this requires analysis of the supply chain of the tobacco industry.

\section{THE INPUT-OUTPUT STRUCTURE OF THE CIGARETTE INDUSTRY}

The input-output (IO) table 2010-2011 provides structural information about the tobacco sector (manufacturing of cigarettes) in Pakistan and its linkages with the rest of the economy. It is 81 by 81 matrix, which gives information about 81 sectors of the economy and provides information about the tobacco industry, separately. It divides the output of industry into the supply to other industries for intermediate consumption and value-added (compensation of employees, consumption of fixed capital and operating surplus). The demand side consists of the intermediate demand by industry, the demand for investment, the final household consumption, the final public consumption and the net exports. The changes in prices and indirect taxes will change the final demand vector.

According to the IO table, the total value of the output of the cigarette industry was Rs 570.0 billion. In order to produce this output, the cigarette industry used intermediate inputs of Rs 283 billion from the agriculture, industry and services sectors (table 3). At the sector level, the cigarette industry used the input of Rs 0.37 from services, Rs 0.07 from industry and Rs 0.05 from agriculture sectors to produce an output of Rs 1 . The value added by the cigarette industry was Rs 287 billion. One important finding is that the supply of this sector is not used as an input in other sectors since cigarettes are the final product directly used for consumption by individuals. In other words, the cigarette industry has no forward linkages, it has only backward linkages.

\section{The share of wages and consumption}

The household sector receives wages for work done in the cigarette industry and spends some or all of this wage income on goods and services. Using the input-output table, table 4 shows the wages and salaries received by employees working in the cigarette industry and final private consumption expenditure by the household on cigarettes. The share of wages in the total value of the output of the cigarette industry is $1.14 \%$, which is much lower compared with other sectors of the economy-the average share of wages in the total value of the output of all sectors of the economy is more than $10 \%$. This indicates that the size of the income multiplier for the cigarette industry is relatively low. The share of final private consumption in total private consumption is 3\%-showing a relatively large consumption-induced effect on the cigarette industry multipliers. 


\begin{tabular}{ll}
\hline $\begin{array}{l}\text { Table } 4 \\
\text { million) }\end{array}$ & Wage and consumption share for the cigarette industry (Rs \\
\hline Heads & $\mathbf{2 0 1 0 - 2 0 1 1}$ value \\
\hline Wages and salaries & 6495 \\
\hline Total value of output & 570041 \\
Share in the total value of output & $1.14 \%$ \\
\hline Household consumption expenditures on cigarettes & 467825 \\
\hline Total household expenditures & $3 \%$ \\
\hline
\end{tabular}

Source: Input-output table of Pakistan economy 2010-2011, prepared by Federal Board of Revenue (FBR).

\section{DATA AND THE METHODOLOGY}

Input-output tables provide a detailed dissection of the intermediate transactions in an economy and are, thereby, a means of describing the supply and use of the products of an entire economic system.

We assume an economy divided into $\mathrm{n}$ sectors. The ratio of input to output, denoted by aij, is termed as a technical coefficient (it is the flow of input from sector $j$ to sector $i$, divided by the total output of sector i). In an input-output analysis, a fundamental assumption is that the technical coefficients are assumed to be fixed, that is, inputs are employed in fixed proportions. This implies that input to output ratio is fixed over time and scale of production. The following model shows the general description of the economy:

$$
\begin{gathered}
{\left[\begin{array}{ccc}
a_{11} & \cdots & a_{1 n} \\
\vdots & \ddots & \vdots \\
a_{n 1} & \cdots & a_{n n}
\end{array}\right]} \\
{\left[\begin{array}{c}
Y_{1} \\
\vdots \\
Y_{n}
\end{array}\right]}
\end{gathered}
$$

Vector X shows the output of each sector. Vector $\mathrm{Y}$ shows the final demand for each sector. The coefficients in matrix A show the amount of extra output required from each industry to produce an extra rupee worth of output from a particular industry.

$$
X=(I-A)^{-1} * \mathrm{YA}
$$

If the inverse $(I-A)^{-1}$ exists then (A) has a unique solution. Matrix A is known as the direct requirements coefficients matrix and the columnwise sum of technical coefficients will give the direct effect of changes in the final demand and $\sum_{j=1}^{n}(I-A)^{-1}$ gives the Type I output multipliers for $\mathrm{j}^{\text {th }}$ sector. As such,

Type I multiplier $=$ initial effect + direct effect + indirect effect

It is assumed that due to a tax rate of the amount ' $\mathrm{t}$ ' the prices of cigarettes have increased by ' $\mathrm{p}$ *, ' and the final demand for cigarettes has decreased by Rs 1 billion. In other words, the tax rate is increased by such a level that will reduce the final demand for cigarettes by Rs 1 billion. This is the initial effect, which is an exogenous shock to the final demand and is shown by $\mathrm{D}$ in equation B. in other words, D shows the changes in the final demand of cigarettes and we assumed it to be 1 for cigarette industry and 0 for all other sectors of the economy. $X^{*}$ shows the simulated impact of changes in final demand on the output of the different sectors of the economy.

$$
X^{*}=(I-A)^{-1} * \mathrm{D}
$$

D shows the change in the final demand vector, which is 1 for the tobacco industry and 0 for all other sectors in our case.

The direct effect gives the impact of changes in the final demand of the cigarette manufacturing sector on the demand of inputs required from all other sectors of the economy.

The indirect effect shows the impact of changes in the final demand of cigarettes on the output, income and employment of the sectors which supply inputs to the sectors that supply inputs to the cigarette industry.

Type II multipliers incorporate household behaviour in the model. A new matrix B is created by adding a row that shows sectorwise compensation of employees (wage bill) divided by the total value of output and a column that reflects household final consumption of each industry divided by total household consumption expenditures. To differentiate, we call it matrix $B$ rather than matrix $A$. In our case, matrix $B$ has an order of $82 * 82$. This allows for an analysis of the impact of changes in the final demand on the economy after including the household consumption and wages of the employed labour into the model.

Type II multipliers for a sector $\mathrm{i}$ is the column sum of $(I-B)^{-1}$. The $(I-B)^{-1}$ has one more column and a row than the $(I-A)^{-1}$. The elements of $(I-B)^{-1}$ are larger than those of the $(I-A)^{-1}$ because they include extraoutput required to meet the consumption-induced output effects.

Type II multiplier $=$ initial effect + direct effect + indirect sales + induced effect

Consumption-induced effects=type II multiplier - type I multiplier

\section{Output multipliers}

The equations 1, 2 and 3 below will have three row vectors T1, T2 and T3:

$$
\begin{gathered}
T 1=\sum_{i=1}^{n} a_{i 1} \\
T 2=\sum_{i=1}^{n}(I-A)^{-1} \\
T 3=\sum_{i=1}^{n}(I-B)^{-1}
\end{gathered}
$$

The sum of each column vector of the A matrix will form a new row vector denoted by T1. Similarly, by adding up each column vector of and $\mathrm{B}^{*}$, we obtain $\mathrm{T} 1, \mathrm{~T} 2$, and $\mathrm{T} 3$, respectively. Let T1', T2' and T3' be the transposes of T1, T2 and T3. The derivation of the output multipliers and their various multiplier effects is then as follows:

The initial effect is equal to changes in the final demand which in this case is one.

The vector T1 gives the direct effect for each industry/sector.

The vector T2 gives the type I multiplier for each industry/ sector.

The vector T2 - T1-the initial effect matrix will give the indirect effect.

The vector T3 gives the type II multipliers for each industry/ sector.

The vector T3 - T2 gives the consumption-induced effect for each industry/sector. 


\section{Income multipliers}

First, we construct vector h, the vector of household income coefficients, which is obtained by dividing the income generated by households in the form of wages and salaries from each sector by the corresponding sector's total value of output. Here, it is assumed that compensation to employees (wages bill) is received by households, which is their income. The following equations are used to estimate the income multipliers:

The vector $h$ will give the initial income effect for each industry/sector.

The vector $\mathrm{h} * \mathrm{~T} 1$ will give the direct income effect for each industry/sector.

The vector $\mathrm{h}$ *T2 will give the type I income multipliers for each industry/sector.

The vector $h * T 2-h * T 1$ will give the indirect income effect for each industry/sector.

The vector $h * T 3$ gives the type II income multipliers for each industry/sector.

The vector $\mathrm{h} * \mathrm{~T} 3-\mathrm{h}$ *T2 gives the consumption induce effect for each industry/sector.

\section{Employment multipliers}

First, vector E is constructed, the vector of employment coefficients, which is obtained by dividing the sector employment by the output of the corresponding sectors. Then, the employment multipliers are derived in a similar way to the income multipliers:

The vector $\mathrm{E}$ will give the initial employment effect for each industry/sector.

The vector $\mathrm{E}^{* \mathrm{~T} 1}$ will give the direct employment effect for each industry/sector.

The vector $\mathrm{E}^{*} \mathrm{~T} 2$ will give the type I employment multipliers for each industry/sector.

The vector $\mathrm{E}^{* \mathrm{~T} 2}-\mathrm{E}^{* \mathrm{~T}} 1$ will give the indirect employment effect for each industry/sector.

The vector $\mathrm{E}^{*} \mathrm{~T} 3$ gives the type II employment multipliers for each industry/sector.

The vector $\mathrm{E}^{*} \mathrm{~T} 3-\mathrm{E}^{*} \mathrm{~T} 2$ gives the consumption-induced effect for each industry/sector.

\section{RESULTS}

This section provides estimates of income, output, and employment multipliers for the cigarette industry in order to measure the macroeconomic impact of changes in tobacco use on different sectors of the economy.

\section{Output multipliers}

We now present the output multiplier effects for changes in demand for the cigarette industry. The output multiplier for the cigarette industry is defined as the total value of production by all industries of the economy required to produce one extra rupee worth of final demand for that industry's output.

To estimate the output multipliers, the first task is to estimate the technical coefficient for cigarette manufacturing, which indicates the direct effect of changes in the production of the cigarette industry on other sectors/industries. As shown earlier, cigarette production used intermediate inputs of Rs 0.5 to produce an output of Rs 1.0, implying that if the final demand of the sector is decreased by Rs 1.0 billion, the cigarette industry will reduce its demand for input by Rs 0.5 billion from other sectors. Table 5 presents the industrywise breakdown of the direct effect of changes in the output of the cigarette industry on the other sectors. The major sectors with backward linkages to the cigarette industry include trade, paper and printing, tobacco and
Table 5 Intermediate inputs used by the cigarette industry (industries with the highest direct effect)

\begin{tabular}{lcl}
\hline Industries & $\begin{array}{l}\text { Direct effect } \\
\text { Value of input } \\
\text { (Rs million) }\end{array}$ & $\begin{array}{l}\text { (Value of Input/total } \\
\text { value of the output of } \\
\text { the cigarette industry) }\end{array}$ \\
\hline Trade & 188358 & 0.330 \\
\hline Paper and printing & 38240 & 0.067 \\
\hline Tobacco & 27343 & 0.048 \\
\hline Road & 20664 & 0.036 \\
\hline Other chemicals & 1878 & 0.003 \\
\hline Railway & 1861 & 0.003 \\
\hline Insurance & 1565 & 0.003 \\
\hline Electricity, water works and supply & 866 & 0.002 \\
\hline Refined petroleum & 402 & 0.001 \\
\hline Other sectors & 1872 & 0.003 \\
\hline Direct effect & 283049 & 0.50 \\
\hline Source: & & \\
\hline
\end{tabular}

Source: Input-output table of Pakistan economy 2010-2011, prepared by Federal Board of Revenue (FBR).

roads. These four sectors would absorb $97 \%$ of the total direct effect, with the trade sector being the largest. The trade sector includes wholesale and retail trade which is a major economic activity involving purchasing inputs and selling the final output; paper and printing is the second-largest input supplier as the paper is used as a major input in packing and wrapping of cigarettes. Raw tobacco is also an important input for cigarettes, and finally, transport is a major input for supplying these inputs to the cigarette industry and supplying final products in the market.

The indirect effect shows the impact on the sectors which supply inputs to the input-supplying sector of the cigarette industry. The indirect effect is estimated to be 0.41 .

Table 6 provides the estimates of type I (simple) output multiplier and type II (total) output multiplier. The simple multiplier does not include the changes in output due to changes in consumption and wages. Accordingly, the value of the simple multiplier (1.91) indicates that a Rs 1.0 billion decrease in final demand for cigarettes will reduce the output of the economy by Rs 1.9 billion.

Consumption expenditure by households also leads to additional demand (or output) in the economy. This induced production of extra goods and services is referred to as the consumption-induced effect. The total multipliers are calculated considering the initial effects, the production-induced effects and the consumption-induced effects. The total output multiplier for the 'cigarette industry' in Pakistan is estimated to be 2.90. This implies that an additional output of Rs 2.9 is required from all industries to satisfy an increased consumption of Rs

\begin{tabular}{ll} 
Table 6 & Output multipliers for the cigarette industry of Pakistan \\
\hline Type of multipliers & Cigarette industry \\
\hline A.Initial effect & 1.000 \\
B.Direct effect & 0.50 \\
C.Indirect effect & 0.41 \\
D.Type I (simple) & 1.91 \\
E.Consumption-induced effect (F-D) & 0.99 \\
F.Type II (total) multiplier & 2.90
\end{tabular}

Source: Input-output table of Pakistan economy 2010-2011, prepared by Federal Board of Revenue (FBR). 
Table 7 Income multipliers for cigarette industry

\begin{tabular}{ll}
\hline Type of multipliers & Cigarette industry \\
\hline A.Initial effect (share of wages \% of total value of output) & 0.008 \\
B.Direct effect & 0.065 \\
C.Indirect effect & 0.146 \\
D.Simple multiplier & 0.167 \\
E.Consumption-induced effect (F-C) & 0.217 \\
F.Total multiplier & 0.385 \\
\hline
\end{tabular}

1.0 in the cigarette industry, as well as to satisfy the additional demand generated by the increased wages, salaries and supplements resulting from all increased output. In other words, the output of the economy will decrease by Rs 2.9 billion due to a reduction of Rs 1.0 billion in the final demand for cigarettes.

It is important to note that the magnitude of the output multiplier of the cigarette industry is on the smaller side compared with other sectors of the economy. For instance, the magnitude of multipliers of the top five sectors ranges between 5.37 and 8.59, which include beverages, cooking oil, fuel, sugar, and construction. The bottom five sectors are insurance, slaughtering, pulses, retail trade, and housing where the size of multipliers lies between 2.35 and 2.57 .

\section{Income multipliers}

The wage income multiplier is defined as the change in the total value of income from wages, salaries and supplements due to change in the final demand for the output of an industry. As mentioned earlier, the share of wages and salaries in the cigarette industry is $1.14 \%$ of the total value of the output of the cigarette industry (table 4), implying that a change in final demand would lead to a small wage income effect.

Estimates for type I and type II wage income multipliers for the cigarette industry in Pakistan are presented in table 7. The results show that a reduction of Rs1.0 billion in the final demand for cigarettes will have an initial effect of Rs 0.008 billion on the income of the people employed in the cigarette industry. The sectors which directly supply inputs to the cigarette industry will decrease the demand for labour and their wage bill will be reduced by Rs 0.065 billion (direct effect). The wage bill of the sectors that supply inputs to the input-supplying sector of the tobacco industry will be reduced by Rs 0.15 billion (indirect effect). The simple wage income multiplier shows that the wage income in the economy will decline by Rs 0.167 billion. Subsequently, this decrease in the income level will lead to lower consumption expenditure. The estimates show that due to a decrease in final demand, the consumption-induced effect on income will be Rs 0.217 billion.

Finally, the value of the total wage income multiplier (0.385) implies that due to a decrease of Rs 1.0 billion in the final demand of cigarettes, the income level in the economy will decline by Rs

\begin{tabular}{lcll}
\hline Table 8 & Employment coefficient & & \\
\hline & $\begin{array}{l}\text { Output } \\
\text { (Billion Rs) } \\
\text { (A) }\end{array}$ & $\begin{array}{l}\text { People } \\
\text { employed } \\
\text { (000's (B) }\end{array}$ & $\begin{array}{l}\text { Employment } \\
\text { Coefficient } \\
\text { C=B/A*1000 }\end{array}$ \\
\hline Agriculture & 5658 & 19301 & 3411 \\
\hline Food products & 2960 & 699 & 236 \\
\hline Cigarettes & 570 & 31 & 54 \\
\hline Textiles & 2269 & 1008 & 444 \\
\hline Paper and printing & 366 & 165 & 450 \\
\hline
\end{tabular}

Table 9 Employment multipliers for the cigarette industry (to produce an output of RS 1 billion)

\begin{tabular}{lc}
\hline Type of multipliers & Cigarette industry \\
\hline A.Initial effect (employment coefficient) & 54 \\
B.Direct effect & 27 \\
C.Indirect effect & 21 \\
\hline D.Simple Multiplier (type I multiplier) & 101 \\
E.Consumption-induced effect (F-D) & 20 \\
\hline F.Total Multiplier (type II multipliers) & 121
\end{tabular}

0.385 billion. Thus, the impact of the wage income multiplier is very small compared with the other sectors of the economy.

\section{Employment multipliers}

Employment multipliers measure the effect on employment of one-unit change in the final demand for cigarettes. The first step is to estimate the employment coefficient for all the sectors included in the input-output table, which are calculated by dividing the number of employed persons in a given industry by the total value of the output of that industry. Table 8 gives the employment coefficients of a few sectors

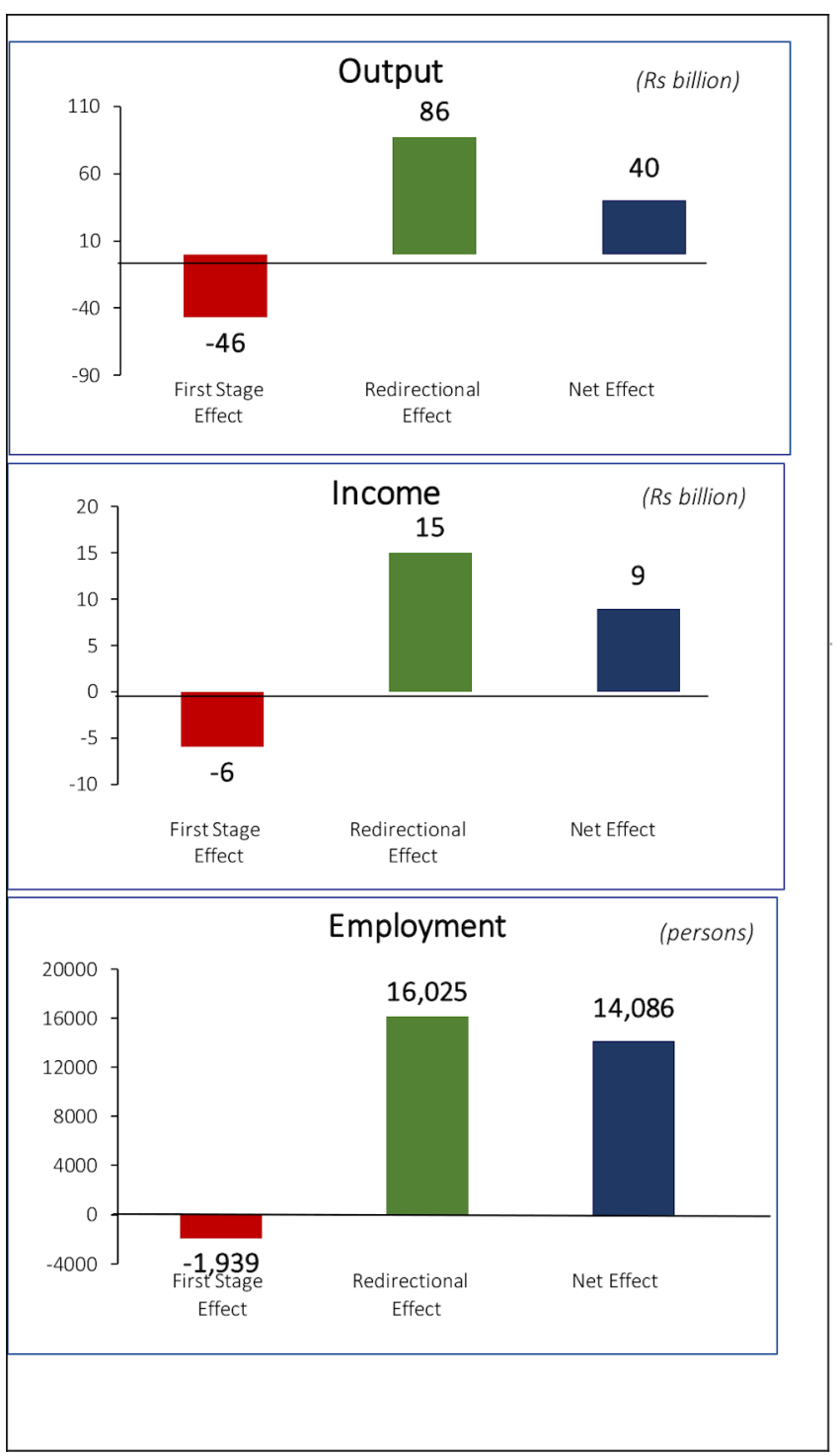

Figure 1 Impact of reduction in tobacco consumption on the economy 
for comparison. The employment coefficient shows that if the output of the cigarette industry decreases by Rs 1 billion, employment in this sector will decrease by 54 persons. It is evident that the employment effect in the cigarette industry is the lowest among all other sectors of the economy since it is not a labor-intensive sector.

The effect based on the employment coefficient can be seen as the initial effect (table 9). Further, the direct effect and indirect effect are estimated to be 27 and 21, respectively. Thus, the simple employment multiplier shows that the overall employment will be reduced by 101 persons. Finally, after adjusting for the consumption-induced effect, the value of the total employment multiplier indicates that due to the Rs 1 billion decrease in the final demand of cigarettes, the total employment loss to the economy would only be 121 persons.

\section{Simulation: expenditure switching from tobacco to food items}

The reduction in cigarette consumption would allow individuals to spend their savings on other commodities depending on their consumption preferences. While the analysis of consumption elasticities is beyond the scope of the study, we developed a scenario to simulate the macroeconomic impact of a tobacco-free economy. This simulation is based on the following assumptions:

Based on the latest estimates of price elasticity of demand, ${ }^{6}$ the analysis shows that a $10 \%$ increase in price will lead to an $11 \%$ reduction in cigarette consumption. Given the total estimated expenditure of Rs 150 billion on cigarettes, this would translate into a household saving of Rs 16 billion in a year, due to a reduction in consumption expenditure on tobacco products. We conducted a simulation exercise with the assumption that individuals would spend $50 \%$ of the saved income (from reduced tobacco use) on food-related products and $50 \%$ on the education of their children. To compute the redirectional impact of tobacco use we used food and education multipliers. The results show that a Rs 16 billion reduction in consumer expenditure on cigarettes will lead to a net increase of Rs 40 billion in the output of the economy. Initially, reducing tobacco consumption will reduce the output of the economy by Rs 46 billion due to a reduction in cigarette industry production. But consumers will spend the money that they saved from not using tobacco on other goods and services. This will lead to an increase in output by Rs 86 billion. Therefore, the net effect would be a Rs 40 billion increase in output. Similarly, the effects on income and employment are also positive (see figure 1).

One of the limitations of the study is that it assumes a $100 \%$ redirectional impact of tobacco use. It treats tobacco taxes and prices exogenously. This is a general limitation of the IO model, which can be addressed by using a computational general equilibrium model, but the latter requires an updated social accounting matrix (SAM). Unfortunately, the latest available SAM of Pakistan is outdated and it does not provide information about the tobacco industry separately. ${ }^{11}$

\section{CONCLUSIONS AND POLICY IMPLICATIONS}

The findings show a small contribution of the tobacco sector into the national economy of Pakistan. For instance, despite being one of the largest tobacco-growing countries, tobacco is not a major crop in Pakistan and accounts for less than half of a percent of the total value of agricultural produce and only $0.2 \%$ of the total area under cultivation. Likewise, the cigarette industry is not a major contributor in the manufacturing sector and Gross Domestic Product (GDP), with a 1\% share in total value added of large-scale manufacturing and less than a half per cent in industrial employment.

The macroeconomic impacts of reducing cigarette consumption were looked into by tracing out backward and forward linkages. The estimates of gross output, income, and employment multipliers based on the input-output table for the cigarette industry have relatively small magnitudes. This implies that changes in consumption of cigarettes will generate relatively small impacts on the other sectors of the economy in general and on the overall economy. Reduction in tobacco consumption will lead to initial losses to the economy but there will be considerable gains in output, employment and income if expenditures are redirected to other sectors with high multipliers.

These findings are in contradiction to the tobacco industry's claim that a decline in consumption of cigarettes leads to a huge loss in output, employment and income of the people working in the tobacco sector and allied activities. Therefore, the findings suggest adopting policies to reduce tobacco use will not have any significant impact on the economy.

\section{What this paper adds}

What is already known on this subject

- The increase in prices leads to a reduction in the consumption of tobacco, but we do not know how they affect the output, income and employment in the other sectors related to the tobacco sector.

\section{What this paper adds}

- This study estimates the changes in output, income and employment resulting from changes in tobacco use.

- The cigarette industry has a small contribution in terms of its share in the economy.

- Reduction in tobacco consumption will lead to initial losses to the economy, but there will be considerable gains in output, employment and income if expenditures are redirected to other sectors.

Contributors This article is based on research report entitled 'Macroeconomic Impacts of Tobacco Use in Pakistan'. The authors are Research Associate and DMD, respectively, at the Social Policy and Development Centre (SPDC).

Funding SPDC is funded by the University of Illinois at Chicago's (UIC) Institute for Health Research and Policy to conduct economic research on tobacco taxation in Pakistan. UIC is a core partner of the Bloomberg Philanthropies' Initiative to Reduce Tobacco Use.

Disclaimer The views expressed in this document cannot be attributed to, nor do they represent, the views of UIC, the Institute for Health Research and Policy, or Bloomberg Philanthropies.

Competing interests None declared.

Patient consent for publication Not required.

Provenance and peer review Not commissioned; externally peer reviewed.

Data availability statement Data are available on reasonable request. the study uses input output table for Pakistan economy, these are developed by Federal Board of Revenue, Government of Pakistan.

ORCID iD

Wasim Saleem http://orcid.org/0000-0002-9511-7628

\section{REFERENCES}

1 The Nation. Alarming number of tobacco users in Pakistan: report the nation, 2018. Available: https://nation.com.pk/19-Apr-2018/alarming-number-of-tobacco-users-inpakistan-report 
2 Ali N, Jaffar A, Anwer M, et al. The economic analysis of tobacco industry: a case study of tobacco production in Pakistan. International Journal of Research 2015;2.

3 Majid A, Usman B, Usmama M, et al. Pakistan tobacco company: strategic analysis, 2017. Available: https://www.academia.edu/35375255/Pakistan_Tobacco_Company_ Strategic_Analysis?auto=download

4 Hu TW, Mao Z. Effects of cigarette tax on cigarette consumption and the Chinese economy. Tob Control 2002;11:105-8.

5 Mushtaq N, Mushtaq S, Beebe LA. Economics of tobacco control in Pakistan: estimating elasticities of cigarette demand. Tob Control 2011;20:431-5.

6 Nayab DE, Nasir M, Memon JA, et al. Economics of tobacco taxation and consumption in Pakistan, 2018Retrieved from. Available: https://pide.org.pk/research/economics-oftobacco.Pdf
7 Qasim H. The demand for tobacco products at household level in Pakistan. Mphill thesis. Islamabad, Pakistan: Department of Health Economics, Pakistan Institute of Development Economics, 2015.

8 Shahid Javed Burki Institute of Public Policy at NetSol. Tobacco: curbing its use. [Internet], 2009. Available: http://www.sjbipp.org/publications/PR/projectreport/PR03-08.pdf [Accessed 12 Jan 2018].

9 Cevik S. Smoke screen: estimating the Tax pass-through to cigarette prices in Pakistan. Rev Dev Econ 2018:22:e1-15.

10 Food and Agricultural Organization of the United Nations. FAOSTAT, 2016. Available: http://faostat.fao.org/site/291/default.aspx [Accessed 12 Sep 2018]

11 Debowicz D, Dorosh PA, Robinson S, et al. A 2007-08 social accounting matrix for Pakistan. PSSP working paper 1. Washington, D.C: International Food Policy Research Institute (IFPRI), 2012. http://ebrary.ifpri.org/cdm/ref/collection/p15738coll2/id/127137 